\title{
Relationship Between Overexpression of EML4-ALK Variant 1 and Inflammatory Moleculars and Immune Mediators Associated with Tumor Progression and Metastasis in BEAS-2B and H2126 Cells
}

\author{
Yang Chen, Ping Wang* \\ Department of Respiratory Medicine, $306^{\text {th }}$ Hospital of PLA, Beijing, China \\ Email address: \\ pingwang306@126.com (Ping Wang) \\ ${ }^{*}$ Corresponding author
}

To cite this article:

Yang Chen, Ping Wang. Relationship Between Overexpression of EML4-ALK Variant 1 and Inflammatory Moleculars and Immune Mediators Associated with Tumor Progression and Metastasis in BEAS-2B and H2126 Cells. American Journal of Clinical and Experimental Medicine. Vol. 4, No. 4, 2016, pp. 103-108. doi: 10.11648/j.ajcem.20160404.13

Received: May 12, 2016; Accepted: June 16, 2016; Published: June 17, 2016

\begin{abstract}
The aim of this study was to investigate the relationship between overexpression of EML4-ALK and inflammatory factors about tumor progression and metastasis in a human bronchial epithelial cell (BEAS-2B) and a lung cancer cell (H2126). The recombinant plasmids with EML4-ALK variant 1 and EML4-ALK K589M (EML4-ALK variant 1 kinase inactive mutant) fusion gene were constructed and introduced into H2126 and BEAS-2B cells after transfection. The plasmid pcDNA3.1 was negative control. Subsequent, cell proliferation assay and scratch wound healing assay were used to examine the proliferation and invasion of BEAS-2B and H2126 cells after transfection. Finally, we analyzed 24 inflammatory moleculars and immune mediators associated with tumor progression and metastasis. Compared to the empty vector as control, the expression level of ALK was upregulated in BEAS-2B and H2126 cells after transfection the plasmid EML4-ALK variant 1 and plasmid EML4-ALK K589M. In vitro, EML4-ALK variant 1 promoted the proliferation and invasion ability of BEAS-2B and H2126 cells compared with EML4-ALK K589M and empty vector. The results of Q-PCR showed that factors more differentially expressed between both groups of BEAS-2B and H2126 cells were S100A8 and S100A9 after transfection EML4-ALK variant 1. In conclusion, an increased expression level in S100A8 and S100A9 by overexpression EML4-ALK variant 1 had a great biological interest because of their relation with tumor cell proliferation and migration.
\end{abstract}

Keywords: EML4-ALK Variant 1, Proliferation, Migration, S100A8, S100A9

\section{Introduction}

Lung cancer remains the number one cause of cancer-related deaths worldwide in 2016 [1]. It is divided into non-small cell lung cancer (NSCLC) and small cell lung cancer (SCLC). NSCLC is the most common type of lung cancer and accounts for $80 \%$ of all lung cancers [2]. Most of the patients are diagnosed at advanced stage and survival rates for advanced disease remain low [3, 4]. With standard first-line chemotherapy with four to six cycles of platinum-based doublet chemotherapy, long-term survival for patients with advanced disease remains poor [5]. Therefore, a better understanding of cancer molecular mechanisms is expected to improve cancer prevention, diagnosis and treatment $[6,7]$.

The molecular targeted drugs of NSCLC have been introduced into routine clinical treatment since the presence of specific oncogenic alterations, including epidermal growth factor receptor (EGFR) gene mutations and anaplastic lymphoma kinase (ALK) rearrangements. EGFR inhibitors and echinoderm microtubule associated protein like 4-anaplastic lymphoma kinase (EML4-ALK) inhibitors can be useful for specific subgroups of patients [8,9]. EML4-ALK, a novel transforming fusion gene, was 
identified in NSCLC in 2007 [10]. But its pathogenetic mechanisms in NSCLC remain unclear [11, 12]. Tumor microenvironment is a crucial role in tumor pathophysiology, including cancer initiation, progression and metastasis [13, 14]. In tumor microenvironment, inflammatory cells and immune mediators influence tumor progression and metastasis in cancers [15]. Therefore, the aim of the present study was to evaluate 24 factors associated with inflammatory molecular and immune mediators influence tumor initiation, progression and metastasis in lung epithelial cells and lung cancer cells by overexpressing EML4-ALK.

\section{Materials and Methods}

\subsection{Cell Lines}

The cell lines used here included NSCLC cell line with a triple negative genotype (H2126, no EGFR mutation, Kras mutation and EML4-ALK fusion gene) and human bronchial epithelial cell (BEAS-2B). The cell lines were obtained from the American Type Culture Collection (ATCC, USA). BEAS-2B cell line was cultured in BEBM (Lonza, USA), at $37^{\circ} \mathrm{C}$ with $5 \% \mathrm{CO}_{2}$. $\mathrm{H} 2126$ cell line was cultured in DMEM (Gibco, USA) supplemented with 10\% fetal bovine serum (Gibco, USA) at $37^{\circ} \mathrm{C}$ with $5 \% \mathrm{CO}_{2}$.

\subsection{The Construction of Plasmids and Transfection in Vitro}

EML4-ALK variant1 is the most common type of EML4-ALK fusion variants $[10,16]$. Therefore, to analyse the function of EML4-ALK, we generated expression plasmid pcDNA3.1 for EML4-ALK variant 1 and EML4-ALK K589M (EML4-ALK variant 1 kinase inactive mutant, in which Lys 589 in the ATP-binding site of the kinase domain is replaced with Met) $[10,14]$. The plasmid pcDNA3.1 was negative control. The plasmid pcDNA3.1, plasmid EML4-ALK variant 1 and plasmid EML4-ALK K589M were separately introduced into BEAS-2B and H2126 cells by Lipofectamine 2000 (Invitrogen, USA). Western blot analysis was used to identify the BEAS-2B and H2126 cells expressing EML4-ALK variant 1 and EML4-ALK K589M.

\subsection{Western Blot Analysis}

BEAS-2B and H2126 cells were seeded onto 6 well culture-plates before transfection. At $24 \mathrm{~h}$ after transfection plasmid into BEAS-2B and $\mathrm{H} 2126$, the cells were collected and lysed on ice in a buffer containing $50 \mathrm{mM}$ Tris $\mathrm{HCl}, \mathrm{pH}$ $7.5,150 \mathrm{mM} \mathrm{NaCl}, 0.5 \%$ Nonidet P-40 and protease inhibitors. Proteins were quantitated by BCA assay (Thermo Scientific Pierce, USA). The proteins of the lysate were separated in $10 \%$ sodium dodecyl sulphate-polyacrylamide gel electrophoresis (SDS-PAGE) and blotted onto the PVDF membranes. Then the membranes were blocked with $5 \%$ bovine serum albumin and incubated with a monoclonal rabbit anti-ALK antibody (1:1000 dilution, Cell Signaling Technology, USA) or a mouse anti-GAPDH monoclonal antibody (1:2000 dilution, abcam, USA) at $4^{\circ} \mathrm{C}$ overnight. After washed, the membranes were incubated with horseradish peroxidase-labelled secondary goat anti-rabbit antibody (dilution 1:2000; Dako, Denmark) or goat anti-mouse antibody (dilution 1:2000; Dako, Denmark) for $2 \mathrm{~h}$ at room temperature and enhanced chemoluminescence (Millipore Corporation, Billerica, USA) in substrate for 5 to $20 \mathrm{~min}$.

\subsection{Cell Proliferation Assay}

BEAS-2B and H2126 cells were transfected with plasmid pcDNA3.1, plasmid EML4-ALK variant 1 and plasmid EML4-ALK K589M. At 24h following transfection, 3000 cell/well were seeded in 96-well plates. After $72 \mathrm{~h}$ incubation, cell proliferation was determined by Cell Titer 96AQueous One Solution Cell Proliferation Assay (MTS assay) kit (Promega, USA).

\subsection{Scratch Wound Healing Assay}

The migration ability of the cells was assessed by scratch wound healing assay. BEAS-2B and H2126 cells were transfected with plasmid pcDNA3.1, plasmid EML4-ALK variant 1 and plasmid EML4-ALK K589M. A 3mm wound was introduced across the diameter of each plate until the cells were growth about $90 \%$ confluency after transfection. BEAS-2B cell migration was observed by microscopy at $72 \mathrm{~h}$ later and analyzed objectively using Image J. H2126 cell migration was observed by microscopy at $24 \mathrm{~h}$ later and analyzed objectively using Image $\mathrm{J}$.

\subsection{Quantitative Real-Time Reverse-Transcription PCR (Q-PCR)}

BEAS-2B and H2126 cells were seeded onto 6 well culture-plates before transfection. At $24 \mathrm{~h}$ after transfection plasmid into BEAS-2B and $\mathrm{H} 2126$, the cells were collected and lysed by Trizol (Invitrogen, USA). Total RNA was extracted with Trizol and quantified using the ND-1000 spectrophotometer (Nanodrop, USA). Complementary DNA was synthesized from $1 \mu \mathrm{g}$ total RNA using a Revert Aid First Strand cDNA Synthesis Kit (Thermo Scientific, USA) following the manufacturer's instructions.

Q-PCR was performed to analyze the mRNA expression of 24 factors (Table 1). Q-PCR reactions were performed in triplicate and using the SYBR ${ }^{\circledR}$ Premix Ex Taq ${ }^{\mathrm{TM}}$ Perfect Real Time kit (Takara, Japan) in an Applied Biosystems 7500 Fluorescent Quantitative PCR System (Applied Bio-systems, USA). The reaction mixtures were incubated at $95^{\circ} \mathrm{C}$ for $30 \mathrm{~s}$, followed by 40 amplification cycles of $95^{\circ} \mathrm{C}$ for $5 \mathrm{~s}$ and $60^{\circ} \mathrm{C}$ for $34 \mathrm{~s}$.

The relative expression levels of mRNAs between samples were calculated by the comparative delta CT (threshold cycle number) method $\left(2^{-\Delta \Delta \mathrm{CT}}\right)$ implemented in the 7500 Real-Time PCR System software. The representation of $2^{-\Delta \Delta \mathrm{CT}}$ was fold changes in the relative gene expression than of target [17]. Primer sequences were presented in Table 2. 
Table 1. Factors analyzed by $Q-P C R$.

\begin{tabular}{ll}
\hline Symbol & Official name \\
\hline CXCL1 & Chemokine (C-X-C motif) ligand1 \\
CXCL3 & Chemokine (C-X-C motif) ligand3 \\
CXCL5 & Chemokine (C-X-C motif) ligand5 \\
CCL3 & Chemokine (C-C motif) ligand3 \\
G-CSF & Granulocyte colony-stimulating factor \\
GM-CSF & Granulocyte-macrophage colony stimulating factor \\
IL-1 & Interleukin 1 \\
IL-4 & Interleukin 4 \\
IL-5 & Interleukin 5 \\
IL-6 & Interleukin 6 \\
IL-8 & Interleukin 8 \\
IL-10 & Interleukin 10 \\
IL-12 & Interleukin 12 \\
IL-13 & Interleukin 13 \\
IFN $\alpha$ & Interferon alpha \\
IFN $\beta$ & Interferon beta \\
MMP2 & Matrix metalloprotease 2 (gelatinase A) \\
MMP9 & Matrix metalloprotease 9 (gelatinase B) \\
M-CSF & Macrophage colony stimulating factor \\
S100A8 & S100 calcium binding protein A8 (calgranulin-A) \\
S100A9 & S100 calcium binding protein A9 (calgranulin-B) \\
TNF & Tumor necrosis factor \\
TGF $\beta 1$ & Transforming growth factor beta 1 \\
TGF- $\alpha$ & Transforming growth factor alpha \\
VEGFA & Vascular endothelial growth factor A \\
\hline
\end{tabular}

Table 2. Primer sequence and product size used for qRT-PCR.

\begin{tabular}{|c|c|c|}
\hline Genes & Primer sequence & Product size (bp) \\
\hline CXCL1 & $\begin{array}{l}\text { F-TCTTCCCTAGGAGCGTCCG } \\
\text { R-GATGCAGGATTGAGGCAAGC }\end{array}$ & 179 \\
\hline CXCL3 & $\begin{array}{l}\text { F-AAAGCTTGTCTCAACCCCGC } \\
\text { R-CACCCTGCAGGAAGTGTCAAT }\end{array}$ & 131 \\
\hline CXCL5 & $\begin{array}{l}\text { F-TGTGCAATTAACAAAGCTACTGC } \\
\text { R-AGGCATCTAAAAAGCTCAGCA }\end{array}$ & 128 \\
\hline CCL3 & $\begin{array}{l}\text { F-GCTCTCTGCAACCAGTTCTCT } \\
\text { R-CACTGGCTGCTCGTCTCAA }\end{array}$ & 125 \\
\hline G-CSF & $\begin{array}{l}\text { F-AGAAGCTGGTGAGTGAGTGTG } \\
\text { R-GGTAGAGGAAAAGGCCGCTA }\end{array}$ & 168 \\
\hline GM-CSF & $\begin{array}{l}\text { F-CTCTGGGATCCCTCAGCTCT } \\
\text { R-GTTCTGGGGAGGTAAACGGG }\end{array}$ & 148 \\
\hline IL-1 & $\begin{array}{l}\text { F-AACCTCTTCGAGGCACAAGG } \\
\text { R-GGCGAGCTCAGGTACTTCTG }\end{array}$ & 107 \\
\hline IL-4 & $\begin{array}{l}\text { F-TCTTCCTGCTAGCATGTGCC } \\
\text { R-TGTGTTCTTGGAGGCAGCAA }\end{array}$ & 155 \\
\hline IL-5 & $\begin{array}{l}\text { F-ACCCAGGAAGCGGGACAATA } \\
\text { R-GCAGCTCCAAGAGCTAGCAA }\end{array}$ & 135 \\
\hline IL-6 & $\begin{array}{l}\text { F-CTCAATATTAGAGTCTCAACCCC } \\
\text { CA } \\
\text { R-GAGAAGGCAACTGGACCGAA }\end{array}$ & 163 \\
\hline IL-8 & $\begin{array}{l}\text { F-AGAGTGGACCACACTGCGC } \\
\text { R-ACATCCCAACGGTCTACGTTA }\end{array}$ & 251 \\
\hline IL-10 & $\begin{array}{l}\text { F-CAACTGGCTCCCCTTACCTT } \\
\text { R-GAGGCTGGATAGGAGGTCCC }\end{array}$ & 153 \\
\hline IL-12 & $\begin{array}{l}\text { F-ACTCTGGAAAGAATGCCACAAT } \\
\text { R-ACCATGACTCACTTGGCTGC }\end{array}$ & 119 \\
\hline IL-13 & $\begin{array}{l}\text { F-TCTGCAATGGCAGCATGGTA } \\
\text { R-GCATCCTCTGGGTCTTCTCG }\end{array}$ & 117 \\
\hline $\mathrm{IFN} \alpha$ & $\begin{array}{l}\text { F-TCGTATGCCAGCTCACCTTT } \\
\text { R-CAGTCAGCATGGTCCTCTGT }\end{array}$ & 162 \\
\hline IFN $\beta$ & $\begin{array}{l}\text { F-TGCTCTGGCACAACAGGTAG } \\
\text { R-AGCCTCCCATTCAATTGCCA }\end{array}$ & 192 \\
\hline MMP2 & $\begin{array}{l}\text { F-GTCTGTGTTGTCCAGAGGCA } \\
\text { R-CTAGGCCAGCTGGTTGGTTC }\end{array}$ & 106 \\
\hline MMP9 & $\begin{array}{l}\text { F-CCTGGGCAGATTCCAAACCT } \\
\text { R-GTACACGCGAGTGAAGGTGA }\end{array}$ & 172 \\
\hline
\end{tabular}

\begin{tabular}{|c|c|c|}
\hline Genes & Primer sequence & Product size (bp) \\
\hline M-CSF & $\begin{array}{l}\text { F-CCAAACTCACCAGGATGCTCA } \\
\text { R-TCCACTCCCAATCATGTGGC }\end{array}$ & 140 \\
\hline S100A8 & $\begin{array}{l}\text { F-GGCCAAGCCTAACCGCTATAA } \\
\text { R-CGGCATGGAAATTCCCCTTT }\end{array}$ & 185 \\
\hline S100A9 & $\begin{array}{l}\text { F-CGGCTTTGACAGAGTGCAAG } \\
\text { R-GCCCCAGCTTCACAGAGTAT }\end{array}$ & 105 \\
\hline TNF & $\begin{array}{l}\text { F-CACAGTGAAGTGCTGGCAAC } \\
\text { R-AGGAAGGCCTAAGGTCCACT }\end{array}$ & 185 \\
\hline TGF- $\beta 1$ & $\begin{array}{l}\text { F-ATGGAGAGAGGACTGCGGAT } \\
\text { R-TAGTGTTCCCCACTGGTCCC }\end{array}$ & 167 \\
\hline TGF- $\alpha$ & $\begin{array}{l}\text { F-CAGGGTGCGGAGATGGAAC } \\
\text { R-CGAGGGCTCACGAGGAAGT }\end{array}$ & 253 \\
\hline VEGFA & $\begin{array}{l}\text { F-CTGTCTAATGCCCTGGAGCC } \\
\text { R-ACGCGAGTCTGTGTTTTTGC }\end{array}$ & 124 \\
\hline
\end{tabular}

\subsection{Statistical Analysis}

All statistical analyses were performed by using SPSS version 18.0 (SPSS, Chicago, IL, USA). Differences between groups were analyzed using Student's t test, one-way ANOVA and Chi-square test. Datasets were described using descriptive statistics as means $\pm \mathrm{SD}$ and differences were considered statistically significant at $P<0.05$.

\section{Results}

\subsection{Overexpression of the EML4-ALK Gene by Liposome-Mediated Transfection in BEAS-2B and H2126 Cells}

Subsequent to $24 \mathrm{~h}$ of EML4-ALK transfection, the transfection of the ALK gene into BEAS-2B and H2126 cells was detected by western blotting. As shown in Figure 1, a successful transfer of EML4-ALK by the liposome complex was confirmed by western blotting of ALK protein. In the plasmid EML4-ALK variant 1-transfected cells and plasmid EML4-ALK K589M-transfected cells, the protein expression levels of ALK were upregulated. By contrast, no band was observed in the empty vector-plasmid pcDNA3.1-transfected cells.

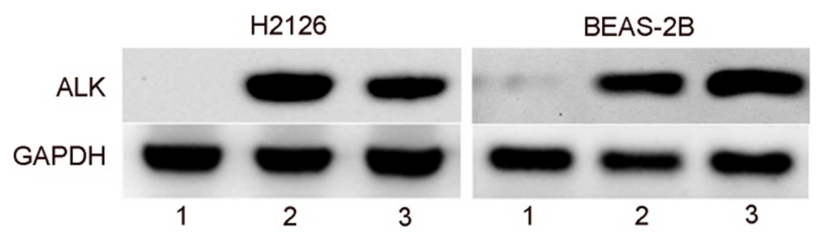

Figure 1. Western blot analysis of ALK protein in BEAS-2B and H2126 cells by transfection plasmid EML4-ALK variant 1 and EML4-ALK K589M. Lane 1 plasmid pcDNA3.1-transfected cells; Lane 2: plasmid EML4-ALK variant 1-transfected cells; Lane 3: plasmid EML4-ALK K589M-transfected cells.

\subsection{Overexpression of the EML4-ALK Gene Promoted Cell Proliferation and Cell Migration Ability}

To investigate whether EML4-ALK was involved in the cell proliferation, cell proliferation assay was performed after overexpression of EML4-ALK gene in H2126 and BEAS-2B cells. As shown in Figure 2, the growth of plasmid EML4-ALK variant 1-transfected cells was higher than plasmid EML4-ALK K589M-transfected cells and empty 
vector-plasmid pcDNA3.1-transfected cells $(P<0.05)$. The results demonstrated that EML4-ALK had an effect on cell proliferation.

The migration of BEAS-2B and H2126 cells was increased after transfection of plasmid EML4-ALK variant 1 compared to empty vector-plasmid pcDNA3.1 and plasmid EML4-ALK K589M (Figure 3). The results of quantitative analysis showed a significant increase of BEAS-2B and H2126 cells migration after transfection EML4-ALK variant 1 compared with empty vector-plasmid pcDNA3.1 and plasmid EML4-ALK K589M $(P<0.05)$.

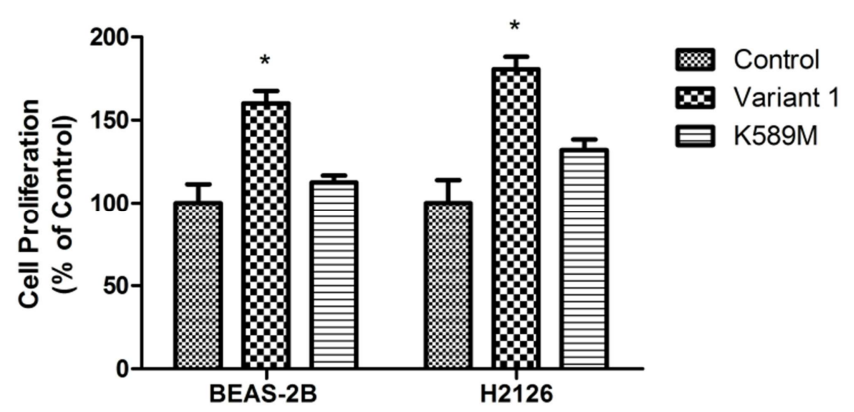

Figure 2. Cell proliferation in BEAS-2B and $H 2126$ cells: the growth of plasmid EML4-ALK variant 1-transfected cells was significantly accelerated compared with empty vector-plasmid pcDNA3.1-transfected cells and plasmid EML4-ALK K589M-transfected cells $(P<0.05$, the symbol * indicates statistically significant). Control: plasmid pcDNA3.1-transfected cells; Variant 1: plasmid EML4-ALK variant 1-transfected cells; K589M: plasmid EML4-ALK K589M-transfected cells.
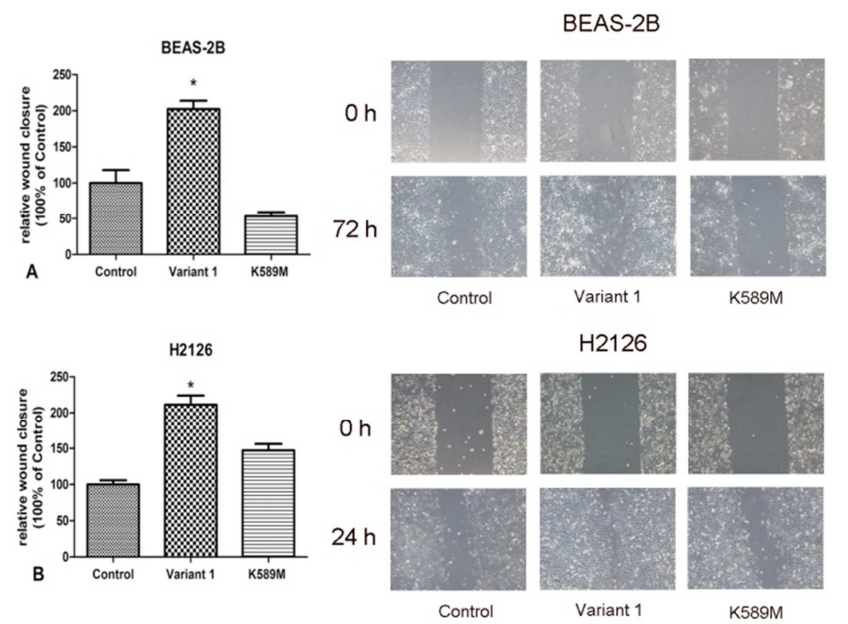

H2126

Figure 3. Scratch wound healing assay in BEAS-2B and H2126 cells: The cell migration of plasmid EML4-ALK variant 1-transfected cells was increased compared with empty vector-plasmid pcDNA3.1-transfected cells and plasmid EML4-ALK K589M-transfected cells $(P<0.05$, the symbol * indicates statistically significant). Control: plasmid pcDNA3.1-transfected cells; Variant 1: plasmid EML4-ALK variant 1-transfected cells; K589M: plasmid EML4-ALK K589M-transfected cells.

\subsection{Preliminary Screening of Factors Related to Inflammatory Molecular and Immune Mediators Influence Tumor Progression and Metastasis After Overexpression of the EML4-ALK Gene}

We analyzed the expression of 24 factors related with inflammatory molecular and immune mediators influence tumor progression and metastasis after transfection by the plasmid EML4-ALK variant 1 and plasmid EML4-ALK K589M through Q-PCR (Table 1). The empty vector-plasmid pcDNA3.1 was negative control. Though quantitative analysis, the results found differences in the RNA expression of 2 factors (S100A8 and S100A9) in BEAS-2B and H2126 cells after transfection (Figure 4). The plasmid EML4-ALK variant 1-transfected cells showed an increase in the mRNA level of S100A8 and S100A9 compared to plasmid EML4-ALK K589M-transfected cells and empty vector-plasmid pcDNA3.1-transfected cells.
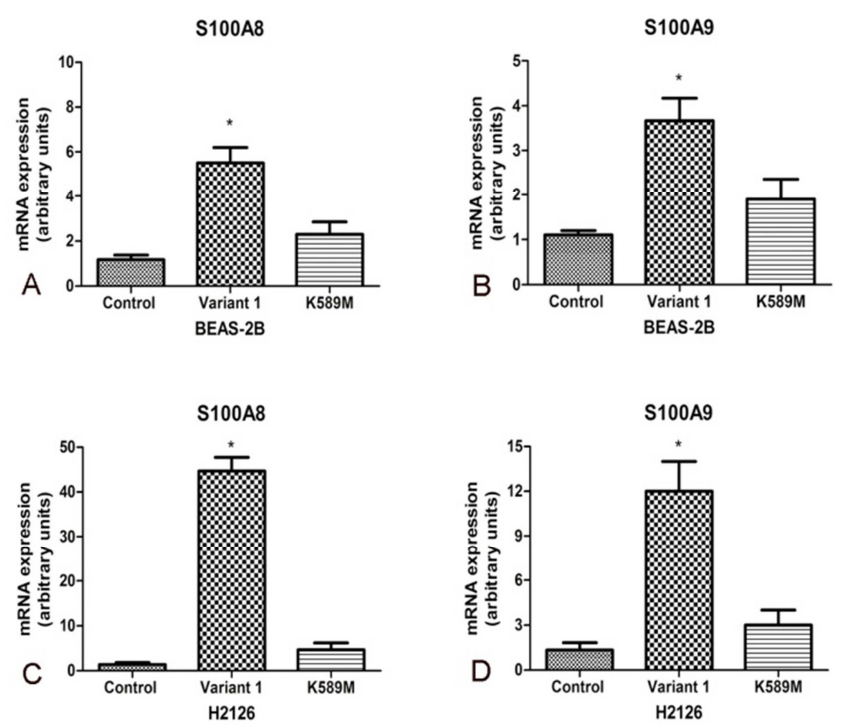

Figure 4. $Q-P C R$ analysis of $S 100 A 8$ and S100A9 differentially expressed in BEAS-2B and H2126 cells by overexpression EML4-ALK: A: S100A8 mRNA expression in BEAS-2B cells; B: S100A9 mRNA expression in BEAS-2B cells; $C$ : S100A8 mRNA expression in H2126 cells; D: S100A9 mRNA expression in H2126 cells $(P<0.05$, the symbol * indicates statistically significant). Control: plasmid pcDNA3.1-transfected cells; Variant 1: plasmid EML4-ALK variant 1-transfected cells; K589M: plasmid EML4-ALK K589M-transfected cells.

\section{Discussion}

EML4-ALK, a novel fusion oncogene, was identified in NSCLC in 2007 [10]. EML4-ALK was formed as the result of a small inversion within the short arm of chromosome 2 because intron 13 of EML4 was disrupted and joined to intron 20 of ALK. Therefore, the fusion protein contained the amino-terminal half of EML4 and the intracellular catalytic domain of ALK $[10,18]$. ALK rearrangements results in the activation of ALK and its downstream signaling pathways displaying tumorigenic activity [11].

At least 14 EML4-ALK variants have been reported in patients with ALK-positive NSCLC [19]. The most common variant is E13:A20 (the nomenclature refers to the exons in EML4 (E) that are fused to ALK (A)) which are referred to as variants $1(\mathrm{v} 1,33 \%)[19,20]$. In this study, we constructed plasmid EML4-ALK variant 1 to overexpression EML4-ALK in NSCLC cell line with a triple negative genotype (H2126) and human bronchial epithelial cell (BEAS-2B). In order to eliminate other factors, we meanwhile constructed plasmid 
EML4-ALK K589M which EML4-ALK kinase was inactive. Compared to the empty vector-plasmid pcDNA3.1, plasmid EML4-ALK variant 1 and EML4-ALK K589M were successfully transferred into BEAS-2B and H2126 cells by western blotting detection.

The results of the functional experiments in vitro showed that plasmid EML4-ALK variant 1 promoted tumor cell proliferation and migration in BEAS-2B and H2126 cells compared to EML4-ALK K589M. Then we performed a preliminary screening of inflammatory molecular and immune mediators influence tumor progression and metastasis in BEAS-2B and H2126 cells after overexpression EML4-ALK variant 1 in order to analyze the relationship between specific inflammatory factors and EML4-ALK. Our results demonstrated that factors more differentially expressed between BEAS-2B and H2126 cells after overexpression EML4-ALK variant 1 were S100A8 and S100A9 by Q-PCR.

In a word, our study showing an increased expression level in S100A8 and S100A9 by overexpression EML4-ALK variant 1 had a great biological interest because of their relation with tumor cell proliferation and migration. S100A8 and S100A9, two members of the S100 family of calcium-binding proteins, have been participated in numerous functions including protein phosphorylation, enzymatic activation, calcium homeostasis, and known to play roles in innate immune system [21, 22]. The overexpression of S100A8 and S100A9 have been reported in association with the tumor cell differentiation and tumor progression [23, 24, 25]. Therefore, the further work is to study the effects of S100A8 and S100A9 in EML4-ALK positive NSCLC in vivo and the mechanisms which cause the S100A8 and S100A9 overexpression.

\section{Conclusion}

Our study investigated the relationship between overexpression of EML4-ALK and inflammatory factors about tumor progression and metastasis in a human bronchial epithelial cell (BEAS-2B) and a lung cancer cell (H2126). The results of Q-PCR showed that factors more differentially expressed between both groups of BEAS-2B and $\mathrm{H} 2126$ cells were S100A8 and S100A9 after transfection EML4-ALK variant 1 . And only EML4-ALK variant 1 exhibited higher proliferation rates and invasion ability compared to the controls indicating a role of EML4-ALK variant 1 of the pathogenetic mechanism in NSCLC. Therefore, an increased expression level in S100A8 and S100A9 by overexpression EML4-ALK variant 1 had a great biological interest because of their relation with tumor cell proliferation and migration. The data may provide the next research direction for molecular pathogenesis of EML4-ALK positive lung cancer.

\section{Acknowledgement}

This study was supported by the Science Foundation for Young Scientists of $306^{\text {th }}$ Hospital of PLA (14QN04).

\section{References}

[1] Siegel RL, Miller KD, Jemal A. Cancer statistics, 2016. CA Cancer J Clin. 2016 Jan, 66(1):7-30. doi: 10.3322/caac.21332

[2] Siegel R, DeSantis C, Virgo K, Stein K, Mariotto A, Smith T, Cooper D, Gansler T, Lerro C, Fedewa S, Lin C, Leach C, Cannady RS, Cho H, Scoppa S, Hachey M, Kirch R, Jemal A, Ward E. Cancer treatment and survivorship statistics, 2012. CA Cancer J Clin. 2012 Jul-Aug, 62(4): 220-241. doi: 10.3322/caac. 21149

[3] Thun MJ, DeLancey JO, Center MM, Jemal A, Ward EM. The global burden of cancer: priorities for prevention. Carcinogenesis. 2010 Jan, 31(1): 100-110. doi: 10.1093/carcin/bgp263

[4] Ansari J, Shackelford RE, El-Osta H. Epigenetics in non-small cell lung cancer: from basics to therapeutics. Transl Lung Cancer Res. 2016 Apr, 5(2): 155-71. doi:10.21037/tlcr.2016.02.02

[5] Gerber DE, Schiller JH. Maintenance chemotherapy for advanced non-small-cell lung cancer: new life for an old idea. J Clin Oncol. 2013 Mar 10, 31(8): 1009-1020. doi: 10.1200/JCO.2012.43.7459

[6] Tran B, Dancey JE, Kamel-Reid S, McPherson JD, Bedard PL, Brown AM, Zhang T, Shaw P, Onetto N, Stein L, Hudson TJ, Neel BG, Siu LL. Cancer genomics: technology, discovery, and translation. J Clin Oncol. 2012 Feb 20, 3 0(6): 647-660. doi: 10.1200/JCO.2011.39.2316

[7] Tsao AS, Scagliotti GV, Bunn PA Jr, Carbone DP, Warren GW, Bai C, de Koning HJ, Yousaf-Khan AU, McWilliams A, Tsao MS, Adusumilli PS, Rami-Porta R, Asamura H, Van Schil PE, Darling GE, Ramalingam SS, Gomez DR, Rosenzweig KE, Zimmermann S, Peters S, Ignatius Ou SH, Reungwetwattana T, Jänne PA, Mok TS, Wakelee HA, Pirker R, Mazières J, Brahmer JR, Zhou Y, Herbst RS, Papadimitrakopoulou VA, Redman MW, Wynes MW, Gandara DR, Kelly RJ, Hirsch FR, Pass HI. Scientific Advances in Lung Cancer 2015. J Thorac Oncol. 2016 May, 11(5): 613-38. doi: 10.1016/j.jtho.2016.03.012

[8] Fukihara J, Watanabe N, Taniguchi H, Kondoh Y, Kimura T, Kataoka K, Matsuda T, Yokoyama T, Hasegawa Y. Clinical predictors of response to EGFR tyrosine kinase inhibitors in patients with EGFR-mutant non-small cell lung cancer. Oncology. 2014, 86(2): 86-93. doi: 10.1159/000357129

[9] Xie J, Zhang X. The Impact of Genomic Profiling for Novel Cancer Therapy-Recent Progress in Non-Small Cell Lung Cancer. J Genet Genomics. 2016 Jan 20, 43(1): 3-10. doi: 10.1016/j.jgg.2015.09.003

[10] Soda M, Choi YL, Enomoto M, Takada S, Yamashita Y, Ishikawa S, Fujiwara S, Watanabe H, Kurashina K, Hatanaka H, Bando M, Ohno S, Ishikawa Y, Aburatani H, Niki T, Sohara Y, Sugiyama Y, Mano H. Identification of the transforming EML4-ALK fusion gene in non-small-cell lung cancer. Nature. 2007 Aug 2,448(7153):561-566.

[11] Palmer RH, Vernersson E, Grabbe C, Hallberg B. Anaplastic lymphoma kinase: signaling in development and disease. Biochem J. 2009 May 27, 4 20(3): 345-361. doi: 10.1042/BJ20090387 
[12] Mano H. The EML4-ALK oncogene: targeting an essential growth driver in human cancer. Proc Jpn Acad Ser B Phys Biol Sci. 2015, 91(5): 193-201. doi: 10.2183/pjab.91.193

[13] Horsman MR, Vaupel P. Pathophysiological Basis for the Formation of the Tumor Microenvironment. Front Oncol. 2016 Apr 12, 6: 66. doi: 10.3389/fonc.2016.00066

[14] Albini A, Sporn MB. The tumour microenvironment as a target for chemoprevention. Nat Rev Cancer. 2007 Feb, 7(2): 139-147.

[15] Xing Y, Zhao S, Zhou BP, Mi J. Metabolic reprogramming of the tumour microenvironment. FEBS J. 2015 Oct, 282(20): 3892-8. doi: 10.1111/febs. 13402

[16] Morán T, Quiroga V, Gil Mde L, Vilà L, Pardo N, Carcereny E, Capdevila L, Muñoz-Mármol AM, Rosell R. Targeting EML4-ALK driven non-small cell lung cancer (NSCLC). Transl Lung Cancer Res. 2013 Apr, 2(2): 128-41. doi: 10.3978/j.issn.2218-6751.2013.03.04

[17] Livak and Schmittgen: Analysis of relative gene expression data using real-time quantitative PCR and the $2-\Delta \Delta \mathrm{Ct}$ method. Methods 25:402-408, 2001.

[18] Choi YL, Takeuchi K, Soda M, Inamura K, Togashi Y, Hatano S, Enomoto M, Hamada T, Haruta H, Watanabe H, Kurashina K, Hatanaka H, Ueno T, Takada S, Yamashita Y, Sugiyama Y, Ishikawa Y, Mano H. Identification of novel isoforms of the EML4-ALK transforming gene in non-small cell lung cancer. Cancer Res. 2008 Jul 1, 68(13): 4971-4976. doi: 10.1158/0008-5472.CAN-07-6158
[19] Wang H, Yuan J, Ma Z. A new target in non-small cell lung cancer: EML4-ALK fusion gene. Zhongguo Fei Ai Za Zhi. 2011 Jun, 14(6): 538-542. doi: 10.3779/j.issn.1009-3419.2011.06.11

[20] Soda M, Takada S, Takeuchi K, Choi YL, Enomoto M, Ueno T, Haruta H, Hamada T, Yamashita Y, Ishikawa Y, Sugiyama Y, Mano H. A mouse model for EML4-ALK-positive lung cancer. Proc Natl Acad Sci USA. 2008 Dec 16,105(50):19893-19897. doi: 10.1073/pnas.0805381105

[21] Goyette J, Geczy CL. Inflammation-associated S100 proteins: new mechanisms that regulate function. Amino Acids. 2011 Oct, 41(4): 821-842. doi: 10.1007/s00726-010-0528-0

[22] Srikrishna G. S100A8 and S100A9: new insights into their roles in malignancy. J Innate Immun. 2012, 4(1): 31-40. doi: $10.1159 / 000330095$

[23] Arai K, Takano S, Teratani T, Ito Y, Yamada T, Nozawa R. S100A8 and S100A9 overexpression is associated with poor pathological parameters in invasive ductal carcinoma of the breast. Curr Cancer Drug Targets. 2008 Jun, 8(4): 243-252.

[24] Başsorgun Cİ, Unal B, Erin N, Ozlük A, Uzun OC, Elpek GÖ. S100A8 and S100A9 Positive Cells in Colorectal Carcinoma: Clinicopathological Analysis. Gastroenterol Res Pract. 2014, 2014: 943175 . doi: $10.1155 / 2014 / 943175$

[25] Lim SY, Yuzhalin AE, Gordon-Weeks AN, Muschel RJ. Tumor-infiltrating monocytes/macrophages promote tumor invasion and migration by upregulating S100A8 and S100A9 expression in cancer cells. Oncogene. 2016 Apr 18. doi: 10.1038/onc.2016.107 